\title{
The ancient Chinese notes on hydrogeology
}

\author{
Yu Zhou • François Zwahlen • Yanxin Wang
}

\begin{abstract}
The ancient Chinese notes on hydrogeology are summarized and interpreted, along with records of some related matters, like groundwater exploration and utilization, karst springs, water circulation, water conservation and saline-land transformation, mine drainage, and environmental hydrogeology. The report focuses only on the earliest recorded notes, mostly up until the Han Dynasty (206 BC-AD 25). Besides the references cited, the discussion in this report is based mainly on archaeological material, the preserved written classic literature, and some assumptions and/or conclusions that have been handed down in legends to later ages. Although most material relates to ancient China, the lessons learned may have practical significance worldwide. Compared to other contemporary parts of the world, ancient China, without doubt, took the lead in the field of groundwater hydrology. The great achievements and experience of the Chinese ancestors should provide motivation and inspiration for hydrogeologists to carry out their scientific research and exploration passionately and actively.
\end{abstract}

Keywords China - History of hydrogeology · Groundwater exploration · Karst

\section{Introduction}

Groundwater has been a source of water supply since the dawn of recorded history of human settlement and agricultural activity. China has a long history and its

Received: 12 May 2010 / Accepted: 15 November 2010

Published online: 13 January 2011

(C) Springer-Verlag 2011

Y. Zhou $(\bullet) \cdot$ F. Zwahlen

Centre d'Hydrogéologie et de Géothermie (CHYN),

Institut de Géologie et d'Hydrogéologie,

Université de Neuchâtel,

2009, Neuchâtel, Switzerland

e-mail: yu.zhou@unine.ch

Tel.: +41-32-7182692

Fax: $+41-32-7182603$

Y. Zhou $\cdot$ Y. Wang

School of Environmental Studies and MOE Key Laboratory

of Biogeology and Environmental Geology,

China University of Geosciences,

430074, Wuhan, China people had profound insight into, and widespread use of, groundwater at a very early stage. The work summarized in this report involved collection and interpretation of the available historical information on the ancient Chinese perspective on hydrogeology and some related matters. It introduces seven aspects of groundwater utilization and related issues. While hydrogeologists gather groundwaterrelated background data, ancient literature and books should be given as much attention as modern ones. Although numerous historical documents are available, very few hydrogeological records were found scattered among them. It is hard to find them but they are useful for enriching the data and understanding the hydrogeological condition, and some literature contains records of collected data. In addition to introducing the ancient Chinese perspective, one of the aims of this report is to bring passionate interest to hydrogeologists and to further the historical material collection that can be used in their scientific research.

\section{The knowledge and utilization of groundwater in the pre-historic ages}

In spite of numerous disputes over the division of Chinese historical periods, it can be agreed that the 'pre-historic ages' include the Xia Dynasty (2146 BC-1675 BC), Shang Dynasty (1675 BC-1029 BC), Zhou Dynasty (which consists of two eras: Western Zhou, eleventh century BC to $771 \mathrm{BC}$ and Eastern Zhou, $770 \mathrm{BC}-256 \mathrm{BC}$ ) and the earlier primitive commune period before these dynasties.

According to documented Chinese archaeological excavations and historical books, as early as the matriarchal commune period (around 10,000 years ago) in primitive society, spring water has been utilized and shallow wells have been dug. As recorded in "Youwu" (Necessity of training), which is the 19th volume of the book Huainan Zi (literally The Masters/Philosophers of Huainan, a second century BC Chinese philosophical classic from the Han Dynasty that discusses many preHan schools of thought, especially Huang-Lao Daoism), Shennong, considered to be the father of Chinese agriculture, taught his people how to cultivate grain as food so as to avoid killing animals. Shennong was known as the Yan Emperor, the ruler of China and cultural hero who lived some 5,000 years ago and whose name means "the Divine Farmer". He also tasted hundreds of herbs to 
test their medicinal value, from which developed Chinese medicine, and he also taught people to distinguish between the "sweetness and bitterness" of water and springs to get drinkable water.

A spring is the natural emergence of groundwater. Many springs can be directly used without any physical digging, enclosure or drawing, so a spring was, no doubt, the earliest groundwater resource used by ancient people. In the unearthed oracle bone inscriptions (earliest Chinese scripts comprising pictographic characters carved in bones or shells), a lot of places were found to be named after springs, like Huan Spring, Wheat Spring, Rice Spring and so on. There were also some records of people offering sacrifices to springs (Chen 1956). The writing style of "spring" (Fig. 1) in the oracle bone inscriptions was also very vivid, indicating water coming out of a concave terrain (Shen 1979).

Ancient Chinese people not only utilized spring water, they also composed songs and poems about springs. Shi Jing (The Book of Songs, sixth century BC) comprises 305 poems, some possibly written as early as $1,000 \mathrm{BC}$. It forms part of the so-called Five Classics (five ancient Chinese books said to be compiled or revised by Confucius, at least used by Confucianism as the basis of studies) and also the best source of information on the daily lives, hopes, complaints and beliefs of ordinary people in the early Zhou Dynasty. There were about a dozen poems that mentioned springs (Shen 1981), including information such as about their coolness and freshness, their being buried underground, and their quality and quantity changes along with the seasons and so on.

The most interesting finding is that Erya (The Literary Expositor: the oldest Chinese glossary), in the chapter "Explaining Rivers", lists a variety of springs such as "gushing spring", which is consistent with the present term "ascending spring" presenting the phenomenon of water gushing out of the ground; "irrigating spring", which implies "descending spring" describing the water flowing down via gravity and it also gives the image of irrigating the nearby field; "wine spring", which was characterized as being "discharged from caves" (like the

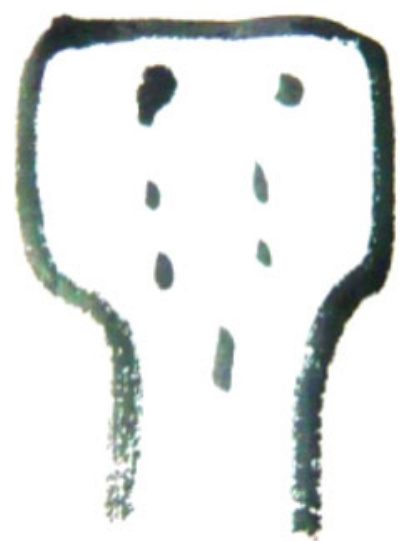

Fig. 1 Oracle bone inscription of "spring" in Chinese $(4,000$ 3,000 years ago) term "karst spring") and probably named "wine spring" because the water from such springs sometimes tasted like wine, as seen from related stories. This series of descriptions was taken as the earliest set of spring categories recorded in Chinese history. Erya was previously said to be written by Confucius and his followers, but later textual study proved it was a scholar in the early Han Dynasty (Han: 206 BC-AD 25) who collected and edited many items of old literature from the Zhou Dynasty to the Han Dynasty, so the classification of springs existed even before the Han Dynasty.

\section{The development of wells and water-lifting devices}

\section{An important trace: Hemudu well}

In 1973, archaeologists discovered the oldest well in China-Hemudu well in Yuyao County, Zhejiang Province, in the lower Yangtze River coastal plain. Based on the C-14 dating of the well wood, it was inferred that the well was built in $3710 \pm 125 \mathrm{BC}$, but the depth was only $1.35 \mathrm{~m}$ (Liu and Yao 1993; Zhejiang Provincial Institute of Cultural Relics and Archaeology 2003). The well site contains over 200 wooden components and can be divided into inner and outer parts. The outer part consists of 28 piles around a pond. The inner part, the wooden well itself, lies in the middle of the pond (Zhejiang Provincial Institute of Cultural Relics and Archaeology and Zhejiang Provincial Museum 1978; Xia 1977). In the excavation area (Fig. 2), the well is surrounded with close-set semicylindrical piles; meanwhile, it is possible to see how another pictographic character “井” (well, pinyin: jing) is derived from this image, even as an oracle bone inscription (Fig. 3). The walls of the well were lined with close-set timber piles reinforced by a square wooden frame. The 28 piles in the outer part of the site may have been part of a shelter for the well, suggesting that the people of the Hemudu culture were already concerned with water hygiene and protection of their water source (Jiao 2007). The appearance of this well, in terms of the significance in the history of the civilization of the human race, symbolized that agriculture had entered into a new era.

At the earliest stage, people performed all activities right near the rivers or streams, since they could not live without water. However, surface-water resources were influenced greatly by the seasonal precipitation and this risk was the driving force for ancient people to explore more stable water resources like groundwater. Ever since the invention of wells, human beings have been able to live far away from surface-water resources, which then greatly expanded their territory of activities. In some ancient books, like in Shi Ben (Origin of the World, written in the Warring States Period [475 BC-221 BC]), it says that "Boyi made the well". Legend tells that Boyi was from the time of Yu Shun, in other words, the time when primitive communes were just about to disintegrate and slavery was about to rise (right before the Xia 


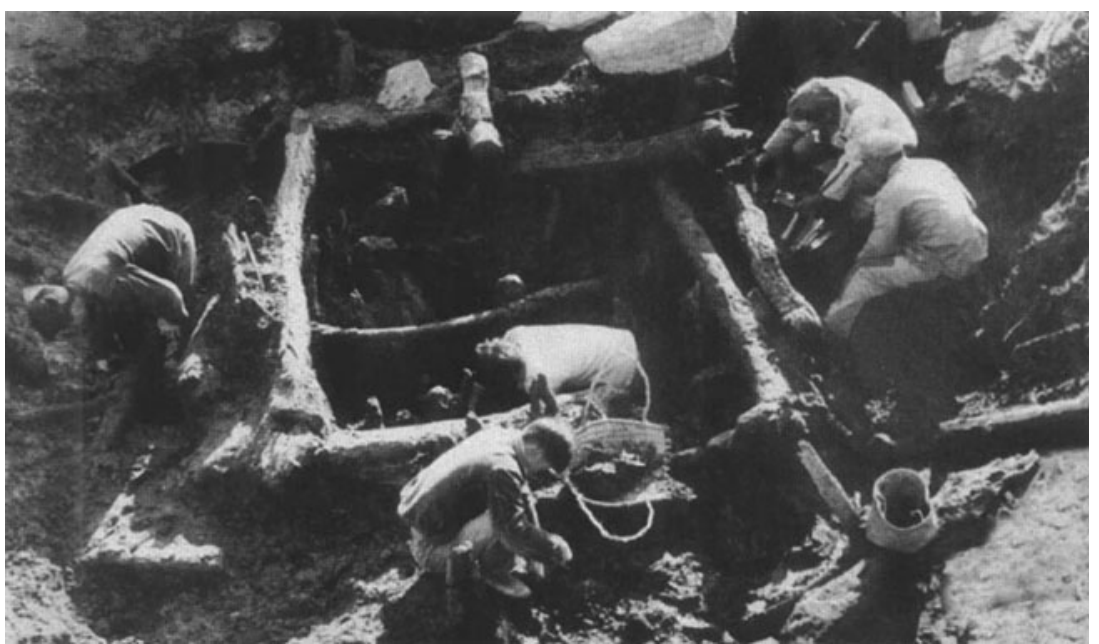

Fig. 2 The Hemudu well under excavation in 1973 (The Museum of the Hemudu site 2002)

Dynasty); however, the Hemudu well was much earlier than this time.

\section{Other traces of wells}

Since Hemudu well has a history dating back around 5,700 years, it could be inferred that relatively more primitive and simpler wells must have been dug before this time. The earliest wells could have been made by natural collapse, which is very common in karst areas, and later people on their own began to dig artificial wells to imitate natural ones. One story written by Sheng Honzhi in the fifth century, in the book Jingzhou Ji (The records of Jingzhou District), tells that a cave in Suizhou county in central China (which was said to be the place Shennong was born) contained nine naturally connected wells and while drawing water from one well, water levels in all other wells changed; the local people named it Shennong Temple and often performed sacrificial rites there year after year. Those documented wells were apparently formed by land collapse.

In Jiangou village of Handan City in Hebei Province, Cuoli village of Luoyang City in Henan Province, and Songjiang County in Shanghai Province, wells from the Neolithic period have also been discovered. (This report refers to the Neolithic period in China, which began about $12000 \mathrm{BC}$ and lasted until about $2000 \mathrm{BC}$.) The first two

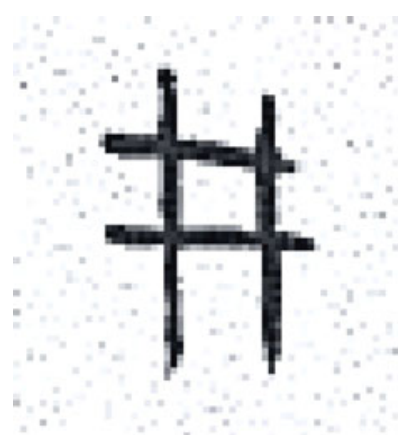

Fig. 3 Oracle bone inscription of "well" in Chinese were the traces of Longshan culture (a late Neolithic culture in China, centered on the central and lower Yellow River and dated from about $3000 \mathrm{BC}$ to $2000 \mathrm{BC}$ ), and the latter one was of late Songze culture, about 5,000 years ago.

Wells from the Shang and Western Zhou dynasties, and from the Spring and Autumn Period $(770 \mathrm{BC}-476 \mathrm{BC})$ and the Warring States Period (475 BC-221 BC), have also been discovered at many sites, which covered not only the central plains but also the Yangtze River basin. The wells are round, oval, square or rectangular in shape and their structures are of wood or stone, with down-hole rings or they are uncased. From all available data, it can be seen that the earliest wooden well was from Neolithic age (Hemudu well); some later discoveries from the Shang Dynasty (Taixi well) and Zhou Dynasty (Jinan well) were also made of wood. The earliest stone well was from the Western Zhou era (Jiaozhuang well). Clay pipe wells were very popular during the Warring States Period, excavated both in Hebei in east China and Shaanxi in west China (Shen et al. 1985). The technique using clay pipes as water drawing pipes was found in the remains of Yin Ruins (the ruins of the last capital of China's Shang Dynasty; the capital served 12 kings in eight generations over 255 years). Some of the discovered clay pipe wells were from the early Eastern Zhou era. This technique was a great improvement in the history of well digging; the pipes were quite large in volume and inconvenient to transport, so when it came to the Han Dynasty, people already knew to connect pieces of pipes or tiles to make things easier.

When China entered the period of the primitive commune system of paternal clans $(2550 \mathrm{BC}-2140 \mathrm{BC})$, and along with the development of settled residence and agriculture production, wells were already widespread with greater depths and better structures. Shen (1979) summarized well history based on the archeological materials as follows: Jiangou well of Handan City in Hebei Province and Cuoli well of Luoyang City in Henan Province of Longshan culture $(2800 \mathrm{BC}-2300 \mathrm{BC})$ : the depths were from 6 to $7 \mathrm{~m}$; Taixi well (in Hebei Province) from the Shang Dynasty was rectangular with a depth of almost $10 \mathrm{~m}$ and wooden rings inside; Jiaozhuang well 
(Donghai County in Jiangsu Province) from the early Western Zhou era was built with stone, and a tile well with a clay down-hole ring was also found from that time.

\section{Water-lifting devices}

Meanwhile, great progress was made in regards to waterlifting tools. In some uncased wells built in the Shang Dynasty, some symmetrical foot prints were found on the side walls, which could be the traces of people climbing up and down while lifting the water. Some wells were big enough in dimension to allow two coordinated buckets to travel up and down. Based on this evidence, Liu (1963) inferred that people used a pulley to lift water, and later they employed a shadoof (device with a bucket on one end and weight on the other) and a windlass (mechanism involving a crank). It is said that shadoofs (Fig. 4) started to be used in the Shang Dynasty, and windlasses (Fig. 5a) were invented by Shi Yi during the early Zhou Dynasty. The oracle bone inscription for windlass (Fig. 5b) describes exactly the image of using a windlass to lift water.

When it came to the Warring States Period (475 BC$221 \mathrm{BC}$ ), from the perspective of well utilization, wells were not only used for domestic water supply (drinking and irrigation). They were also used for drainage and cold storage. At least ten Shang Dynasty wells have been excavated within $200 \mathrm{~m}^{2}$ in Erligang of Henan Province, and in Keshengzhuang of Shaanxi Province, wells were situated every $20-30 \mathrm{~m}^{2}$, probably for collective irrigation supply.

Salt wells emerged quite late. Huayang Guo Zhi (Records of Huayang Kingdom), a book written by Zhang Qu during the Western Jin Dynasty (AD 265-AD 316), documented that Li Bing (who built the famous Dujiangyan Irrigation System) was nominated as the senior officer of Shu (an ancient state in what is now Sichuan) in $250 \mathrm{BC}$ and was in charge of digging salt wells. As stated, Li Bing "knows astronomy and geography" and "recognizes groundwater pulse" (literally translated), which means he understood the local ground-

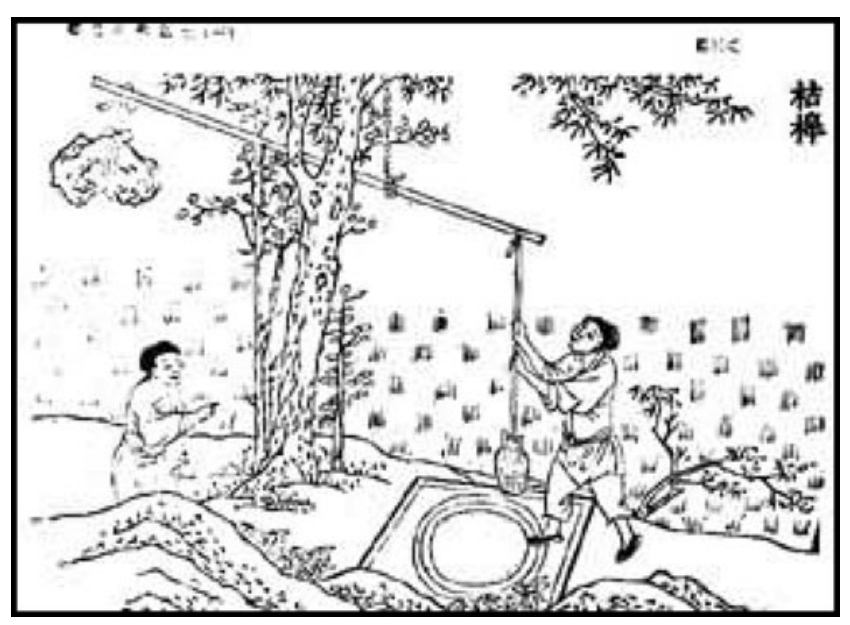

Fig. 4 Shadoof used in ancient China, adapted from Zhou 2008

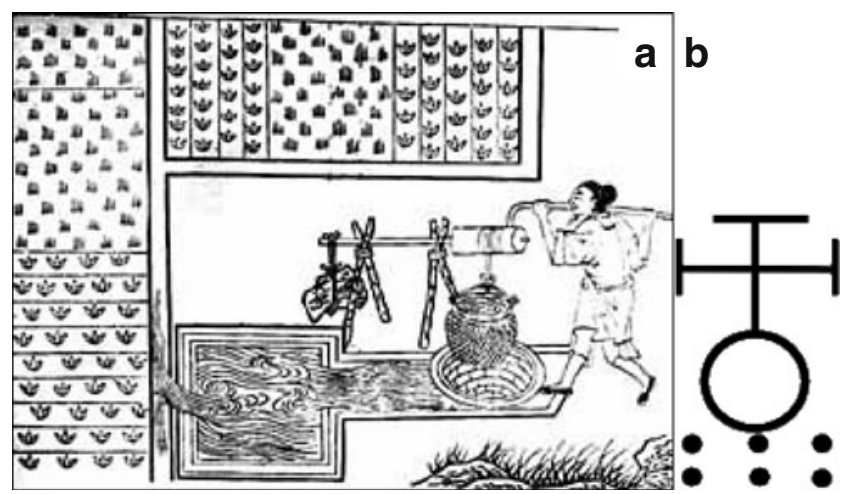

Fig. 5 a Windlass used in ancient China, adapted from Zhou 2008. b Oracle bone inscription of "windlass"

water system and salt deposits. It also said in this book that this technique makes Shu "the land of abundance", and this is the earliest record of a salt well in ancient Chinese history.

\section{Well-digging technology in China}

According to archeological research, way back to the Neolithic Age about 6,000-7,000 years ago, Chinese ancestors had known how to drill a well, and the earliest drilling started with salt wells. At first, wells were dug that were wide in diameter and shallow in depth. It took hundreds of people with shovels and hoes that were used in agriculture. Wooden well-digging rings were used as the well wall, which were replaced by piles later, and then bricks or stones. To dig a well requires a variety of techniques. The Chinese are credited with developing the percussion method of well construction. The 'rope and drop method' invented in Zigong (China) involved a steel rod or piston that was raised and dropped vertically via a rope. In continuous use for 4,000 years (and counting), the percussion system of drilling began with a framework constructed of bamboo that allowed for the raising and dropping of a heavy chiseling or crushing tool. Using this system and the aforementioned original tools (Fig. 6), wells were drilled to depths of $130 \mathrm{~m}$ around 3,000 years ago (Northern Song Dynasty), although construction took generations to complete. The cable tool drilling rig, as we know it today, directly descended from the bamboo framework percussion drilling techniques of the Chinese people.

\section{First signs of environmental hydrogeology}

From the perspective of environmental hydrogeology (i.e. the survey of geologic and hydrologic factors controlling the occurrence, movement and quality of groundwater), the most valuable information in ancient Chinese books is the discussion on the relation between the natural environment and human health, and indicated that environmental conditions were the main cause for some diseases. Two 


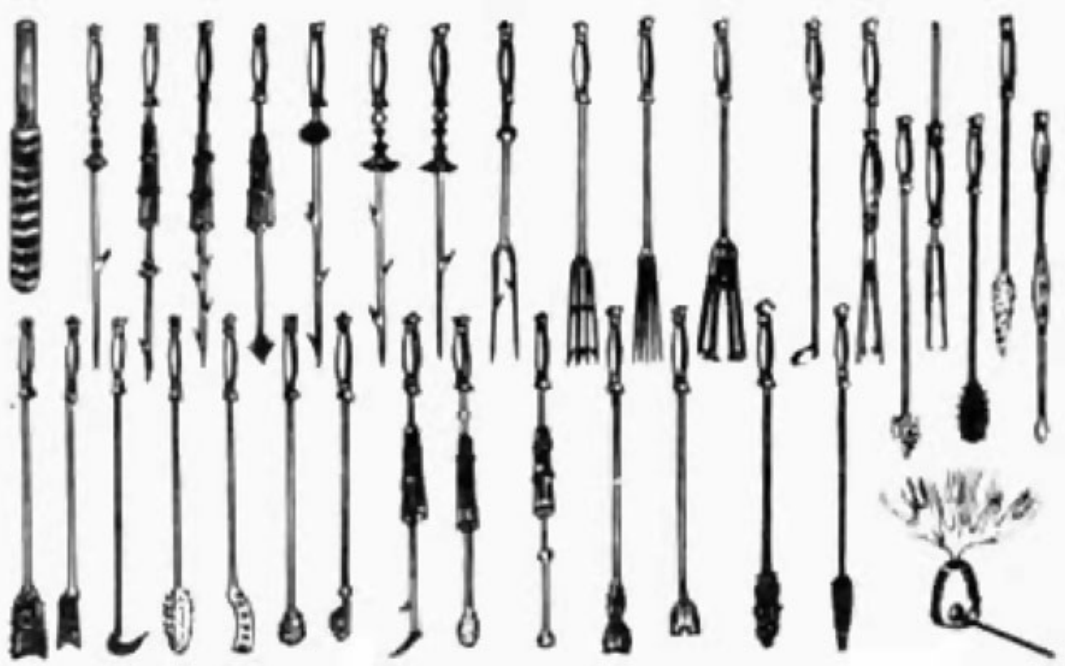

Fig. 6 Ancient Chinese well-drilling tools. Source: Chinabaike 2007

paragraphs in Zuo Zhuan (Zuo's Commentary, the earliest Chinese work of narrative history, covering the period from $722 \mathrm{BC}$ to $468 \mathrm{BC}$ ) recorded: Han Jue from the State of Jin (Jin Guo, one of the states during the Western Zhou Dynasty and the Spring and Autumn Period, based in Shanxi, China) thought that "tu bo shui qian"(meaning "earth thin water shallow" or, the water table is too shallow), can cause "wet disease and swelling feet", which means the malaise caused by high humidity, and people at the place "tu hou shui shen"(earth thick water deep) were "living without diseases". Yi He from the state of Qin considered that the universe has "Yin, Yang, Wind, Rain, Light, Dark"; these six elements must be in balance. "Too much is disaster", which implies none of them should be too much, or it would lead to all kinds of illness, explained later in the same paragraph where water is "light", people were inclined to have alopecia and endemic hypothyroidism; where water is "hard", people were more likely to have lower extremity edema and dyskinesia; where water is "bitter", people were likely to have rickets and dwarfism. This paragraph is very informative, the "light water" refers to "rain water or water from mountains", but from the medical symptom, it would be because of iodine content in the water; "hard water" refers to groundwater but in this context some minerals in the water must be high in content; "bitter water" implies a poor quality water similar to an abnormally high content of nitrate or chloride.

Since water quality can have an impact on human health, sometimes water was also used for treatments. As mentioned before, Shennong tasted different water springs to test their medical effects. According to Bencao Gangmu (Compendium of Materia Medica) written by Li Shizhen (considered to be the greatest naturalist of China, and was very interested in the proper classification of herb components) in the Ming Dynasty, 43 kinds of water/ springs were believed to have medicinal properties. During the pre-Qin Dynasty (221 BC-207 BC), which kind was used medicinally is hard to know, but it is certain that people used hot springs to heal diseases. According to some local chronicles of later ages, as in Shaanxi Tongzhi (Records of Shaanxi Province), Qinshihuang (king of the Chinese State of Qin from $246 \mathrm{BC}$ to $221 \mathrm{BC}$ during the Warring States Period and the first emperor of a unified China from $221 \mathrm{BC}$ to $210 \mathrm{BC}$ ) built a palace at a hot spring in Li Mountain which is only $30 \mathrm{~km}$ away from Xi' an and named it "Li Mountain Soup", which was used for maintaining good health. Therefore, it can be seen that hot springs were used even before the Qin Dynasty. By the Tang Dynasty (AD 618-AD 907), there had already been grand-scale hot spring pools with excellent water inflow and drainage systems.

As appeared in Nong Shu (Book of Agriculture) written by Wang Zhen, in the time of the Tang Emperor (the early Shang Dynasty), during a time of drought, Yi Yin (a prime minister and one of the most honored officials of the early Shang Dynasty) taught people how to dig wells for irrigation and use shadoof technology. Based on this, and the fact that a rectangular well was discovered from the early Shang Dynasty remains, Liu (1963) inferred that this irrigation technology was probably invented in the early Shang Dynasty. From the late Spring and Autumn Period to the time the first feudal dynasty (Qin) was founded, along with the rapid increase in economy, the exploitation and utilization of groundwater was apparently developed.

Shi Ji (The Records of the Grand Historian, written from $109 \mathrm{BC}$ to $91 \mathrm{BC}$ ) was the magnum opus of Sima Qian, in which he recounted Chinese history from the time of the Yellow Emperor up to his own time. The Yellow Emperor, traditionally dated ca. $2600 \mathrm{BC}$, is the first ruler whom Sima Qian considered to be sufficiently established enough historically to appear in the book. Shi Ji recorded that the karez (wells and underground channels) in Turpan of Xinjiang (northwest China) appeared at least before 200-300 BC.

As mentioned before, in $200 \mathrm{BC}$, Li Bing from the Qin Dynasty had already manufactured salt (boiling groundwater to get salt). By the early Han Dynasty (consisting of Western Han: 206 BC-8 BC, Xin Chao: AD 9-AD 23, 
Eastern Han: AD 25-AD 220), the Zigong region in Sichuan had already developed a very prosperous industry of making salt out of high-salinity/brine groundwater and people had dug artesian wells at depths from tens to hundreds of meters.

As well as being the water supply for general human needs and manufacturing, due to its hazardous effects, groundwater has also caused problems for people from time to time over the ages. For instance, land salinization has been a problem due to the shallow depth of groundwater. A geography book called Shang Shu (Classic of History, composed in the Warring States Period), in the chapter "Yu Gong" (The Tribute of [Great] Yu), and the volume Xia Benji (Annals of the Xia Dynasty) in Shi Ji (Records of the Grand Historian), both document the wide distribution of saline soil in the Qingzhou region, to the west of Weifang City, Shandong Province, China. In the latter book it says that people reconverted the saline land into crop fields. Therefore, it can be seen that China had started fighting land salinization approximately as long ago as the seventh century BC.

\section{Ancient knowledge on the characteristics and origin of groundwater}

\section{Water cycle}

In order to explain the origin of groundwater, inevitably it is necessary to have access to the ancient knowledge on the water cycle and understand the ancient perception of the relationship between groundwater and surface water. A valuable clue is that ancient China had explicit concepts about water circulation. Zhou Yi (Classic of Changes or Book of Changes, one of the oldest Chinese classical texts), in the earliest extant version of the text, written on bamboo slips (dating to the latter half of the Warring States Period: mid fourth to early third century BC) contains images of a system of divination. The divination centered on the idea of the dynamic balance of opposites, the evolution of events as a process, and acceptance of the inevitability of change. Some images illustrated all-round knowledge of a variety of water-activity modes. Generally, water falls to the ground in rain, flows out of the ground in springs, forms into rivers and streams, and finally flows into the sea. Where does it go after flowing into the sea? Qu Yuan (ca. 340 BC-278 BC, a Chinese scholar and minister to the King from the southern $\mathrm{Chu}$ during the Warring States Period) asked this and other questions in the book Tian Wen (Heaven Asks), "How were the 'Nine Continents' formed? (China was called Nine Continents by ancient Chinese people because of the regional division at that time) How were the river valleys dredged? Who knows the reason why the East Sea never gets filled up although hundreds of streams flow into it?"

The Taoist book Zhuang Zi (named after its purported author Zhuang $\mathrm{Zi}$, the philosopher) also contains information; since $\mathrm{AD}$ 742, when Emperor Xuanzong of Tang mandated honorific titles for Taoist texts, it has also been known as the Nanhua Zhenjing, literally meaning "True
Classic of Southern Florescence". Its chapter "Qiushui" (Autumn Water) says "after water enters the sea, there is a place called Wei Lü to release it". Liezi, a Daoist text attributed to Lie Yukou (a ca. fifth century BC "Hundred Schools of Thought" philosopher, but Chinese and Western scholars believe it was compiled around the fourth century), contains "Questions of Tang" (chapter 5), which says that there was a huge bottomless gully billions of miles to the east of Bohai Sea (also known as Bohai Gulf, or strictly Bohai, which is the innermost gulf of the Yellow Sea on the coast of northeastern China) and it was called Gui Xu. However, these are more like mythology, while in Lüshi Chunqiu, the section "Junshou" (ruler need practice quiescence) says that "when water flows to the East China Sea, it reaches the apices, so it returns" but it did not say in which way it "returns". Lüshi Chunqiu is literally Mister Lü's Spring and Autumn, an encyclopedic Chinese classic text compiled around $239 \mathrm{BC}$ under the patronage of the Qin Dynasty Chancellor Lü Buwei. In Zhuang Zi, the chapter "Tianyun" (The Revolution of Heaven) related cloud and rain, asking "Is cloud rain? Is rain cloud?" and it seems to indicate that cloud turns into rain and rain turns back into cloud, the direction of the water cycle but not exactly.

The book Huangdi Neijing (The Inner Canon of Huangdi or Yellow Emperor's Inner Canon) is an ancient Chinese medical text that has been treated as the fundamental doctrinal source for Chinese medicine for more than two millennia, right up until today); there are two texts, each comprising 81 chapters. In the first text "Suwen" (Basic Questions), chapter 5, it says "studying nature vital theory of mutual action of yin and yang" gave the positive answer that "clear Yang is the sky, turbid Yin is the earth. Earth qi ascends turning into cloud, celestial qi descends into rain. Rain comes out of earth qi; cloud comes out of celestial qi". The "qi" is a term used in Chinese medicine; in this context it means atmosphere, or air. At first sight, this text is confusing. It said celestial qi turns into rain first but then rain comes from earth qi, as does the cloud. The annotation of this book later explained explicitly that "Cloud ascends and then falls as rain, although rain falls from the sky, it is actually the cloud from the earth qi, so rains comes basically out of earth qi. Rain falls and then cloud ascends, although the cloud ascends from earth, it is actually the rain of celestial qi, so originally cloud comes from celestial qi." This made the relation between cloud and rain very clear, but what made the breakthrough in the concept of "cycle", is Lüshi Chunqiu, section "Yuan Dao" (Circular Law), which implies the principle of circulation - "Cloud moves from east to west nonstop, in summer or in winter (means all the year around), cloud turns into rain while moving west, falls to the ground, and then flows from west to east along the terrain into the sea, the sea water again evaporates into the cloud. Therefore, rain/cloud never dries up, and the sea never brims over. This repeated circular process of small (water source) changing into big (sea), heavy (water) into light (cloud) is called Circular "Law". This text logically indicates the principle of water circulation. 
The book Wenzi (also known as Tongxuan zhenjing, literally meaning "Authentic Scripture of Pervading Mystery") is a controversial Daoist classic allegedly written by a disciple of Laozi. Generations of Chinese scholars have dismissed the Wenzi as a plagiarism or forgery; however, in 1973, some archeologists excavated a $55 \mathrm{BC}$ tomb and discovered Wenzi copied on bamboo strips. It also has some words that could be taken as the footnote for "Circular Law": "Water itself has a law... ascending to sky as rain/dew, descending to moisten the earth...slowly and smoothly circumfluent, without any dissipative loss".

\section{Groundwater origin}

The Shang Shu (Classic of History, one of the Five Confucian Classics, literally meaning Esteemed Documents, and is also known as Shu Jing or Shu), is a compilation of documentary records related to events in the ancient history of China. Its chapter "Hong Fan" (The Great Plan) was said to be composed by Jizi, from the late Shang Dynasty, presenting "the great law of heaven and earth" to King $\mathrm{Wu}$ of Zhou (Zhou Wu Wang, the first sovereign, or ruler of the Chinese Zhou Dynasty, who reigned for $1046 \mathrm{BC}-1043 \mathrm{BC})$. This chapter lists the characteristics of the "Five elements: water, wood, fire, metal, earth", and those related to water were literally translated as "one is called water...water moistens downward...moistening downward makes it salty". "Moistening downward makes it salty" is actually a very general and comprehensive description of the groundwater. Water can moisten things, including the ground. Water flows towards the lower region, like water percolating downward underground. "Moistening downward" expresses that water infiltrates underground, recharging groundwater. "Makes it salty" explains that during the "moistening" process, the salinity from soil dissolved in water and increased its degree of mineralization, and then water became "salty". Along the groundwater-flow direction (ancient people called it "water pulse"), people found that there were more "sweet water" (fresh water) wells upstream and more "salty water" (saline water) wells downstream. Therefore, "Moistening downward makes it salty" covers very extensive aspects, including the dynamics of quality change of both surface water and groundwater.

\section{Basis for water circulation}

The text of Zhou Yi is a set of oracular statements represented by 64 sets of six lines each called hexagrams (卦 guà). Each hexagram is a figure composed of six stacked horizontal lines (爻 yáo), and each line is either Yang (an unbroken, or solid line), or Yin (broken, an open line with a gap in the center). With six such lines stacked from bottom to top there are 64 possible combinations, and thus 64 hexagrams represented. The system used astronomical phenomena to describe good or ill omens. This kind of "Heaven grant signs, good/ill luck told" trick is certainly superstitious but what is underneath could represent the knowledge ancient people had for the natural world. Some interesting hydrogeological phenomena in hexagram figures were used to portend the future of any societal action. Based on these descriptions of phenomena (excluding the social activities), a geological profile with a water cycle could be drawn, as in Fig. 7.

A good example of "Swamp on mountain" (that is, lake on the mountaintop) is Heaven Lake (Lake Tianchi), which is a crater lake on the border between China and North Korea. It lies within a caldera atop the volcanic Baekdu Mountain, a part of the Baekdudaegan mountain range and the Changbai mountain range. This "Swamp on the mountain" phenomena could also be caused by glaciation.

"Water course on mountain" is a very common phenomenon. Concerning this, what is shown in Fig. 7 is a partial depression in metamorphic mountains recharged by groundwater from the weathering zones.

"Cave overlapping cave" represents layers of caves in limestone areas, as shown in the profile. The situation in karst caves is often quite complex. Leakage of water is seen to be happening inside the caves and the groundwater level is often very deep, which is described in Zhou Yi as "overlapping caves, extremely dangerous, water flows but never spills over" and "water keeps coming", implying abundant groundwater resources in karst caves, consistent with the known facts.

"Spring at the bottom of mountain", in this case, is just marked as a spring in the profile, without illustrating any specific cause for its formation. In the case of this profile, the spring is associated with a limestone mountain. If there had been a suitable cave outlet, it would have been a karst spring, but there could be a lot of possible causes for "Spring at the bottom of mountain", e.g. contact springs, seepage springs and fault springs. If the "spring at the bottom of mountain" had been restrained due to the local landform, resulting in a pond or lake where the water had accumulated, it would be "Lake at the bottom of mountain". "Lake at the bottom of mountain" could also be located in a valley; those formed in valleys by glaciations are classic cases.

"Water on the wood" is depicted by wooden loops in a well, a method that is proven to exist in the Hemudu well and Taixi already mentioned in the preceding. "Into the water and water up" means digging into the aquifer and then drawing the water from underground.

"Water in the earth" apparently means groundwater. "Swamp on the earth" indicates that the matrix grain size gets smaller in the aquifer; the water table gets shallower and groundwater finally spills onto the surface, forming the swamp. What was drawn in this profile is exactly the case of an overflowing area in a piedmont plain. "Water on the earth" means surface water, "Swamp without water" means the dried swamp, and these are quite easy to understand.

"Water on the lake" could be understood as atmospheric water falling to the lake while "Wind moves on water" implies intensified evaporation. "Lake ascends to the sky" is supposed to be the evaporation of water. "Sky and water disobey the route" is probably the evaporation process of water vapor ascending because normally it should be water (rain) falling from the sky, leading to "Cloud ascends to the sky". Moreover, "Cloud and thunder" depicts the sky densely covered with clouds 


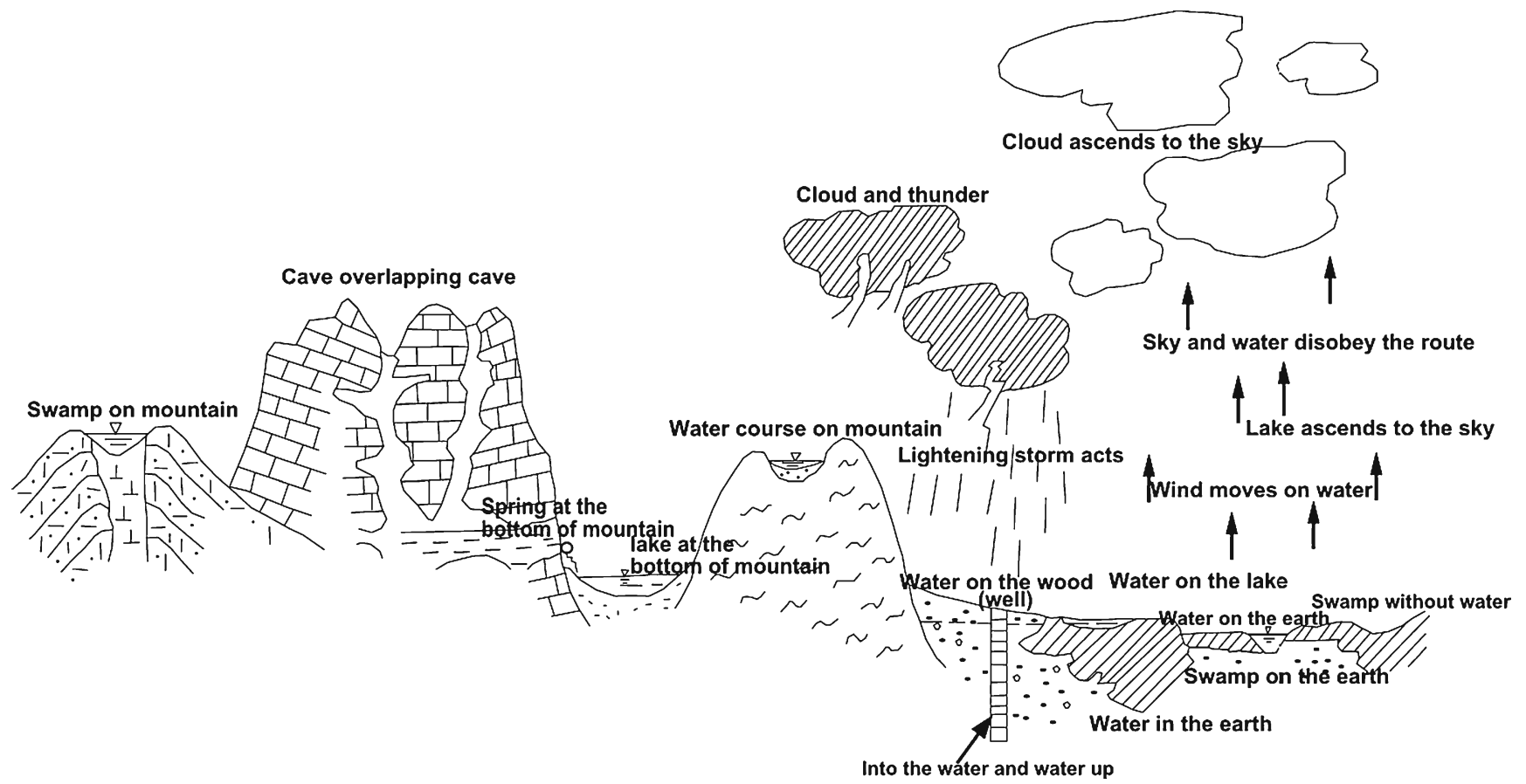

Fig. 7 A geological profile and the water cycle, based on the hexagrams in Zhou Yi, adapted from Shen et al. 1985

and loud thunder, and then "Lightening storm acts", water comes back to the ground from the sky.

It can be concluded that, although the book Zhou Yi did not bring up the issue of water circulation, the 18 divinatory symbols provided every factor that constitutes the water cycle. Putting all these divinatory symbols together makes for a very meaningful water cycle scheme, and it is even more detailed than the water cycle charts in some modern hydrogeology books.

A hexagram text in Zhou Yi says "the place for living can change, but the way of digging well and drawing water for drinking can never change; from this point of view, there is no gain and no loss either. Having drawn water from this and that well, when the well is dry, no one dug the well much deeper and instead they broke all the jars used for drawing water. This is ominous sign."..."The fresh and cool water underground is proper for drinking."..."Putting the well ropes away, removing the well lid and fitting on a windlass, this is auspicious sign."

Plenty of hexagram texts about wells prove that having windlasses is an extremely auspicious sign. "Xici" (Xici Commentary, a part of Zhou Yi) states "well, the place of virtue" and "Tuanzhuan" (Tuanzhuan Commentary, another part of Zhou Yi) says "Well although drawn by people, it never dries up". Kong Yingda, a Tang Dynasty scholar, in his official commentary made it clearer: "well supplies people endlessly, which is the virtue of well; the more you draw, the more it creates; it supplies without an end." By "the more you draw, the more it creates", he means that the water yield and capacity can be ensured if the well is deeply dug and flushed; on the other hand, more advanced water-lifting tools are needed to draw water continuously, and setting up a windlass system could greatly improve the drawing efficiency.
"Dredge the well", that is, cleaning out the well, was certainly necessary to improve the quality and quantity of the groundwater, but "going too far is as bad as not going far enough" (guo you bu ji). If "dredging" went too far, it would also cause bad consequences. For example, if the aquitard was drilled through, it might cause groundwater leakage or percolation of poor-quality water. The book Zhou Yi also says "too much dredging, ominous sign".

\section{Water-conservancy facilities and saline land transformation}

In ancient China, water-conservancy facilities were well developed. According to the book Chinese History on Water Conservancy (Wuhan College of Hydraulic and Electrical Engineering and Institute of Water Resources and Hydropower Research 1979), the most interesting parts are the 12 canals of the Zhang River and Zheng Guo canal. The former was in Wei State (a state during the Warring States Period in China), i.e., nowadays the region of Cixian county and Linzhang county of Hebei Province. In 422 BC, Xi Menbao regulated the Zhang River, and he "led people to dig 12 canals and draw river water to irrigate their croplands", as recorded in "Wei Shijia" (The House of Wei) of Shi Ji (The Records of the Grand Historian). However, Lüshi Chunqiu says that the "drawing Zhang River for irrigation" project was not started by Xi Menbao but by Shi Qi in the King Xiang period of the Wei State. The Zheng Guo canal was in Qin State $(778 \mathrm{BC}-207 \mathrm{BC}$, a state during the Spring and Autumn and Warring States periods of China, in today's Shaanxi Province). Qin State eventually grew to dominate the country and unite it in $221 \mathrm{BC}$, after which it is referred to as the Qin Dynasty. Zheng Guo canal drew water 
from Jing River in northwest Jingyang county to south Fuping county and then into Luo River, crossing through several natural streams with the total length of $150 \mathrm{~km}$. The story behind this project is that Han State sent a water control engineer called Zheng Guo to Qin State in order to talk them into constructing a big water conservancy scheme to use up the labor resources of Qin State. In doing this, they would then be unable to do anything else. However, unexpectedly, after the completion of the project, the strength of Qin State was greatly reinforced.

The conservancy projects certainly had impacts on the dynamics and balance of both groundwater and surface water. According to Lüshi Chunqiu, after people succeeded in the "drawing Zhang River for irrigation" project using the 12 canals of Zhang River, the local people sang the praises of Shi Qi that he finally improved the saline land. With respect to Zheng Guo canal, Shi Ji contains an essay, "Hequ Shu" (Rivers and canals), which describes people using high siltcontent water for warping irrigation, thereby improving the saline land. It can be seen that both cases used warping irrigation to reclaim the saline land. The advantages of warping irrigation were summarized in the treatise section "Gouxu Zhi" (Treatise on rivers and canals) of Han Shu (The History of the Former Han Dynasty, a classical Chinese history finished in $\mathrm{AD} 111$, covering the history of China under the Western Han from $206 \mathrm{BC}$ to $\mathrm{AD} 25)$, and in the chapter "Qingzhong Yi" of Guan Zi (literally "[Writings of] Master Guan", an encyclopedic compilation of Chinese philosophical materials named after the seventh century BC philosopher Guan Zhong, Prime Minister to Duke Huan of Qi), it said that it improved the crop yield many times.

Besides warping irrigation, people also used "washing the soil" techniques to reclaim saline land. Lüshi Chunqiu, in chapter "Ren-di" (Using land), asked "Can you keep our land clean (free of too much saline alkali), using ditches to wash the soil? (Xia 1979)". To wash the saline-alkali soil, there must be a drainage system. In order to lower the groundwater level deeper than the critical depth and then avoid land salinization, the drains should be dug deep. Therefore, in Lüshi Chunqiu, chapter "Bian tu" (differentiate soil), it says that "high ridges had better be flat and wide, ditches narrow and deep". The same expression can be found in Kangcangzi (published in the Tang Dynasty AD 618-AD 907).

\section{Mine drainage}

Guan $Z i$, in the section "Di-shu" (Earth's size), describes that "while metal ore mining in Gelu Mountain, it let out water along with metal ores" and describes another similar situation with respect to "Yonghu Mountain". Both cases imply that groundwater flow was observed while mining. In this context, it is relatively easy to understand why the ancient Chinese thought "groundwater came from metal". This concept is also seen in Gongyang Zhuan (Gongyang's Biography, also called Chunqiu Gongyang Zhuan), authored by Gongyang Gao during the Warring States Period. Gongyang Zhuan explains another book Chunqiu [The Spring and Autumn Annals, the official chronicle of the State of Lu covering the period from $722 \mathrm{BC}$ to $481 \mathrm{BC}$, the earliest surviving Chinese historical text to be arranged on annalistic principles]). Gongyang Zhuan's chapter "Xi Gong 31 nian” (Xi Lord 31th year) says that "mountains and rivers can spread hundreds of li (an old Chinese unit, $1 \mathrm{li}=500 \mathrm{~m}$ )...only Tai Mountain can make rain everywhere under the sky in less than one morning". Mountains are composed of metal ores, so they assumed that water came from metal. In addition, ancient people encountered groundwater so often in mines that they believed that it "was born by metal", as expressed in Guan Zi, chapter "Shui-di" (Water and land).

Some material evidence on mine drainage referred to the ancient copper mines excavated in Tonglü Mountain in Hubei Province, central China. Xia and Yin (1982) reported that the C-14 dating of the excavated wood in Tonglü Mountain showed the earliest mine there was constructed $3,260 \pm 100$ years ago, in other words, the late Shang Dynasty; some other archaeological evidence showed that the latest mine was from $2,075 \pm 80$ years ago, that is, the Western Han Period; most mines were constructed 2,500 2,800 years ago, which is the late Autumn and Spring Period. According to analysis by Xia (1977), the ancient mines were above the water table, but the infiltration of rain and snowmelt water made the drainage system necessary. During the excavation, some discharge canals were also found.

\section{Study on hydrogeological conditions}

The book Guan Zi (authored in the early Warring States Period by Guan Zhong), in section "Di-yuan" (Earth), is a very important document of hydrogeological history. It lists in detail different topography and different soil types and their relation with the groundwater at depth, although in the first place they were rather records of water-bearing regions by ancient people while looking for suitable living places (Shen et al. 1985).

In the text of the first half of section "Di-yuan" (Earth), groundwater was noted, so this document is very useful and provides important information for studying Chinese hydrogeological history. Although the descriptions are of all kinds of terrains, all descriptions mention the depth of groundwater. The first half of the text consists of three parts. The first part discusses plain regions, stating the depth of water/ spring, water quality and its influence on human health related to five terrain types (Table 1). The first terrain type is the "expanding wide plain", that is, the alluvial plain, in modern terms. "Grains thick and plump" means the alluvial plain is fertile, so "five crops grown without inappropriateness" (the ancient five crops being soybeans, rice, wheat, proso millet and foxtail millet) means the crops have plump grains, and the land is lush and fertile. "The water is cyan", and among the 18 types of soil mentioned in the latter half of "Di-yuan" (Earth), three soils are described as bearing groundwater; among those three, two soils bear "cyan" water. One is "fertile soill", "the water white cyan, the people strong, rare scabies, no headache or vertigo"; the other is "situ soil", "the water cyan black, the people straightforward and honest, convenient work and food". In terms of the "color" of groundwater and the condition of health condition 
Table 1 Terrain and groundwater information relating to plain regions, summarized from Guan Zi, section "Di-yuan" (Earth). In the Warring States Period, $1 \mathrm{chi}=23 \mathrm{~cm}$

\begin{tabular}{llll}
\hline Terrain description & Groundwater depth (chi) & Groundwater quality, as described & Suitable crops \\
\hline "Expanding wide plain" & 35 & "Cyan" & Five crops (see text) \\
"Red basin" & 28 & "White cyan and sweet" & Five crops \\
"Brown pond" & 21 & "Brown and stinky" & Millet and broomcorn \\
"Saline and clay soils" & 14 & "Saline" & Beans and wheat \\
"Black clay" & 7 & "Black and bitter" & Rice and wheat \\
\hline
\end{tabular}

of the local people, the characteristics of "fertile soil" and "situ soil" are similar, and they were both top grade soil: "fertile soil" "doesn't crack while dry, doesn't fall apart while wet", "situ soil" "neither agglomerate nor powder into ash, black and loosen, covered with lichen". So these two types are typical soils of the alluvial plain, good for the growth of crops, consistent with the statement "five crops grown without inappropriateness".

The descriptions of the colors for groundwater, e.g. cyan, white cyan, cyan black, are supposed to imply that groundwater has taken up these colors, as observed above the well, although water itself is colorless. The color cyan refers to a greenish blue. On the other hand, assuming the water was obviously colored, it must be high in organic content or mineral content. By modern interpretation, such water is not drinkable and would do harm to health, but the local people were quite healthy, so it confirmed that the water quality was good.

The second terrain type is called "chi lu". "Chi" originally means "red" and "lu" was a kind of rice container, so the terrain shaped in "lu" should be a basin, valley or low land and this region type could be interpreted as "red basin". Many basins in China crop out with Mesozoic red rock layers, Tertiary red soil and Quaternary red loess soil, but it is not certain if the ancient people observed this, which leads to another interpretation. "Chi" could replace another character also pronounced "chi", meaning expanding, vast; in this case, "chi lu" could be "vast basin/valley". "Its water white and people live long" indicated good water quality although their definition of color may be different than nowadays. Besides, above, it says the water coming from "fertile soil" was characterized as "white cyan", so it can be inferred that the soil could be of a similar type. Another soil in this region, called "marron soil", was characterized-"its water clean white, people with sleek complexion" and "less diseases and senility delayed, boys and girls all good-looking".

The third terrain type is "brown pond", which is "swamp". In this text it says " 21 chi till reach the water". (The chi is a traditional Chinese unit of length, approximately equal to one foot or $30 \mathrm{~cm}$, depending on the time history. Its length is derived from the length of the human forearm and first appeared during the Shang Dynasty approximately 3,000 years ago). This corresponds to the fact that although the groundwater can reach the surface in a swamp region, since the earthiness is very fine and bearing a lot of water, permeability and hydraulic conductivity are still very poor and water quality is also bad, so people could only dig the well deep enough to reach the underlying aquifer with coarse lithology. However, they did not have water isolation techniques to prevent contamination by the upper water, so the water is still "brown and stinky". Swamp areas are not suitable for either crops ("inappropriate for any crop but only millet and broomcorn") or for construction ("land is wet and walls are easy to damage, hard to build fortifications"), so it was only possible to "build supported dwellings suspended high above the wet ground" and it was inevitable that "people drift from place to place".

The fourth terrain type is "saline and clay soils" and it is mostly found in coastal areas or the central basin zone. The fifth terrain type is "black clay", which means the land used to be lagoon- or marsh-covered with plenty of plants, so later the water was black with a high organic content. The water tables in these two land/soil-type areas are quite shallow so the water quality is very poor. "Saline and clay soils" were characterized as "14 chi till reach the water" "water saline". "Black clay" was characterized as "7 chi till reach the water", "water black and bitter". Nevertheless, the agricultural production was not necessarily the lowest, according to the record in the "Yu-gong" (The Tribute of [Great] Yu) chapter of Shang Shu. In Shi Ji, the conversion of saline land to crop field, which was mentioned before, made it "suitable for beans and wheat" to yield a good harvest.

The second part of the first half of section "Di-yuan" (Earth) lists 15 hilly lands in order of increasing groundwater depth, from 42 to 140 chi $(10.5-35 \mathrm{~m})$. These hilly lands could be categorized into three classes: (1) valley terrain ("rising extension"), explained as "uplifting flat land near the water", with groundwater depth of " 42 chi" $(10.5 \mathrm{~m})$, i.e. the terraces of valley terrain in hilly areas, "vegetation valley" with shallow groundwater depths, and "non-vegetation valley" with deeper groundwater depths due to soil loss by erosion over time; (2) soil-dominated valleys, with deeper groundwater depth and (3) valleys with both soil and rock, also with quite deep groundwater depth (no details).

The third part of the first half of section "Di-yuan"(Earth) describes mountainous regions, divided into five categories: (1) "suspended water", which refers to perched water or groundwater in the mountaintop weathering zone, with shallow depth - in other words, " 2 chi till reach the water" and "its land is not dry"; (2) "reversing ridge", which implies that an aquitard has blocked the groundwater flow, which is caused by geological structure, raising the water level and forming of a water-storage structure with shallow groundwater depth-" 3 chi till reach the water"; (3)"hollow between two mountains", which also has shallow groundwater depth ("5 chi till reach the water"), covered with hydrophilous plants; (4) "mountain's edge", described as "14 chi till reach the water"; and (5) "mountain's side", described as "21 chi till reach the water". The groundwater depths in the latter two are not very deep. 
In summary, all three parts of Guan Zi, section "Di-yuan" (Earth), described the groundwater depths, and some stated soil or vegetation. Certainly the depths could not be taken as absolute depth but they are still suitable as relative criteria. It can be seen that the groundwater depth in plains and mountains is relatively shallow but deeper in hilly areas.

The book Guan $Z i$ emphasized water a lot. For instance, section "Shui-di" (Water and land) explicitly pointed out that "water gathers from heaven and earth, hidden in everything, born in metal and rock (already explained), exists in all creatures" and thus, water was thought of as the "origin of everything, source of all creatures, cause for human's nature". So "water is the standard for everything", "the reason saints can manage the country lies in water".

All these ideas sound materialistic today but if these are Guan Zhong's opinions, especially the part where water is the origin of everything, it coincidently is in accordance with the ideas of the Greek philosopher Thales. Thales was much younger than Guan Zhong though. The year Guan Zhong died, $643 \mathrm{BC}$, was 3 years before Thales was born. In Europe, the Middle East and Egypt, where human culture developed earlier, groundwater exploitation was going through a similar journey as it did in China, but probably a little bit later. Concerning wells and their structures, the Bible (Genesis) describes public wells from $2000 \mathrm{BC}$, and Ancient Roma widely used springs and wells (depth $<5 \mathrm{~m}$ ) before $312 \mathrm{BC}$. During the Ancient Persian Period (550 BC-330 BC), people in the Tehran region of Iran utilized massive karezs for urban water supply and cropland irrigation, among which the biggest karez was up to $150 \mathrm{~m}$ deep and $26 \mathrm{~m}$ in diameter. The Russian founder of geochemistry, Vladimir Vernadsky (see Vernadsky (1934)), mentioned that twentieth to tenth century BC Greek science already had quite a mature concept about natural water origin and characteristics. In the Roman Empire era (27 BC-AD 476), hot springs were very popular, something that lagged behind China, according to the Chinese historical documents mentioned here (listed in Fig. 8 in the Appendix, and accompanied by a map of China, Fig. 9).

Acknowledgements The first author acknowledges the support from a scholarship from the Centre of Hydrogeology and Geothermics (CHYN), University of Neuchâtel of Switzerland, and help from Prof. Wang Wenke of Chang'an University of China in researching the literature. The authors also wish to thank the editor Dr. Vincent Post, two anonymous reviewers and the technical editorial advisor Sue Duncan for their constructive reviews.

\begin{tabular}{|c|c|c|c|}
\hline Title & Title & Title translation & Period written \\
\hline 诗经 & Shi Jing & The Book of Songs & $1000 \mathrm{BC}$ \\
\hline 左传 & Zuo Zhuan & Zuo's Commentary & $722 \mathrm{BC}$ to $468 \mathrm{BC}$ \\
\hline 尚书 & Shang Shu & Classic of History & $\sim 700 \mathrm{BC}$ \\
\hline 管子 & Guan Zi & Writings of Master Guan & $7^{\text {th }}$ century BC \\
\hline 春秋 & Chunqiu & Spring and Autumn (of Lu State) & $484 \mathrm{BC} \sim 481 \mathrm{BC}$ \\
\hline 周易 & Zhou Yi & Classic of Changes & $4^{\text {th }}-3^{\text {rd }}$ century BC \\
\hline 公羊传 & Gongyang Zhuan & Gongyang's Biography & $475 \mathrm{BC} \sim 221 \mathrm{BC}$ \\
\hline 庄子 & Zhuang Zi & Zhuang $\mathrm{Zi}$ (name of the author) & $369 \mathrm{BC} \sim 286 \mathrm{BC}$ \\
\hline 天问 & Tian Wen & Heaven Asks & $310 \mathrm{BC}$ \\
\hline 吕氏春秋 & Lüshi Chunqiu & Mister Lü's Spring and Autumn & $\sim 239 \mathrm{BC}$ \\
\hline 世本 & Shi Ben & Origin of the World & $234 \mathrm{BC}-228 \mathrm{BC}$ \\
\hline 尔雅 & Erya & The Literary Expositor & before $206 \mathrm{BC}$ \\
\hline 文子 & Wenzi & Authentic Scripture of Pervading Mystery & $\sim 221 \mathrm{BC}$ (not sure) \\
\hline 皇帝内经 & Huangdi Neijing & The Inner Canon of Huangdi & $\sim 221 \mathrm{BC}$ \\
\hline 淮南子 & Huainan $\mathrm{Zi}$ & The Philosophers of Huainan & $2^{\text {nd }}$ century $\mathrm{BC}$ \\
\hline 史记 & Shi Ji & The Records of the Grand Historian & $109 \mathrm{BC}-91 \mathrm{BC}$ \\
\hline 汉书 & Han Shu & The History of the Former Han Dynasty & AD 111 \\
\hline 华阳国志 & Huayang Guo Zhi & Records of Huayang Kingdom & $\mathrm{AD} 265 \sim \mathrm{AD} 316$ \\
\hline 列子 & Liezi & Master Lie & $\mathrm{AD} 4^{\text {th }}$ century \\
\hline 荆州记 & Jingzhou Ji & The Records of Jingzhou District & $\mathrm{AD} 5^{\text {th }}$ century \\
\hline 亢仓子 & Kangcangzi & Kangcangzi (name of the author) & $\sim \mathrm{AD} 742$ \\
\hline 农书 & Nong Shu & Book of Agriculture & $\sim \mathrm{AD} 1300$ \\
\hline 本草纲目 & Bencao Gangmu & Compendium of Materia Medica & $\sim \mathrm{AD} 1587$ \\
\hline 陕西通志 & Shaanxi Tongzhi & Records of Shaanxi Province & AD 1735 \\
\hline
\end{tabular}

Fig. 8 Chinese literature referred to in the article

\section{Appendix}




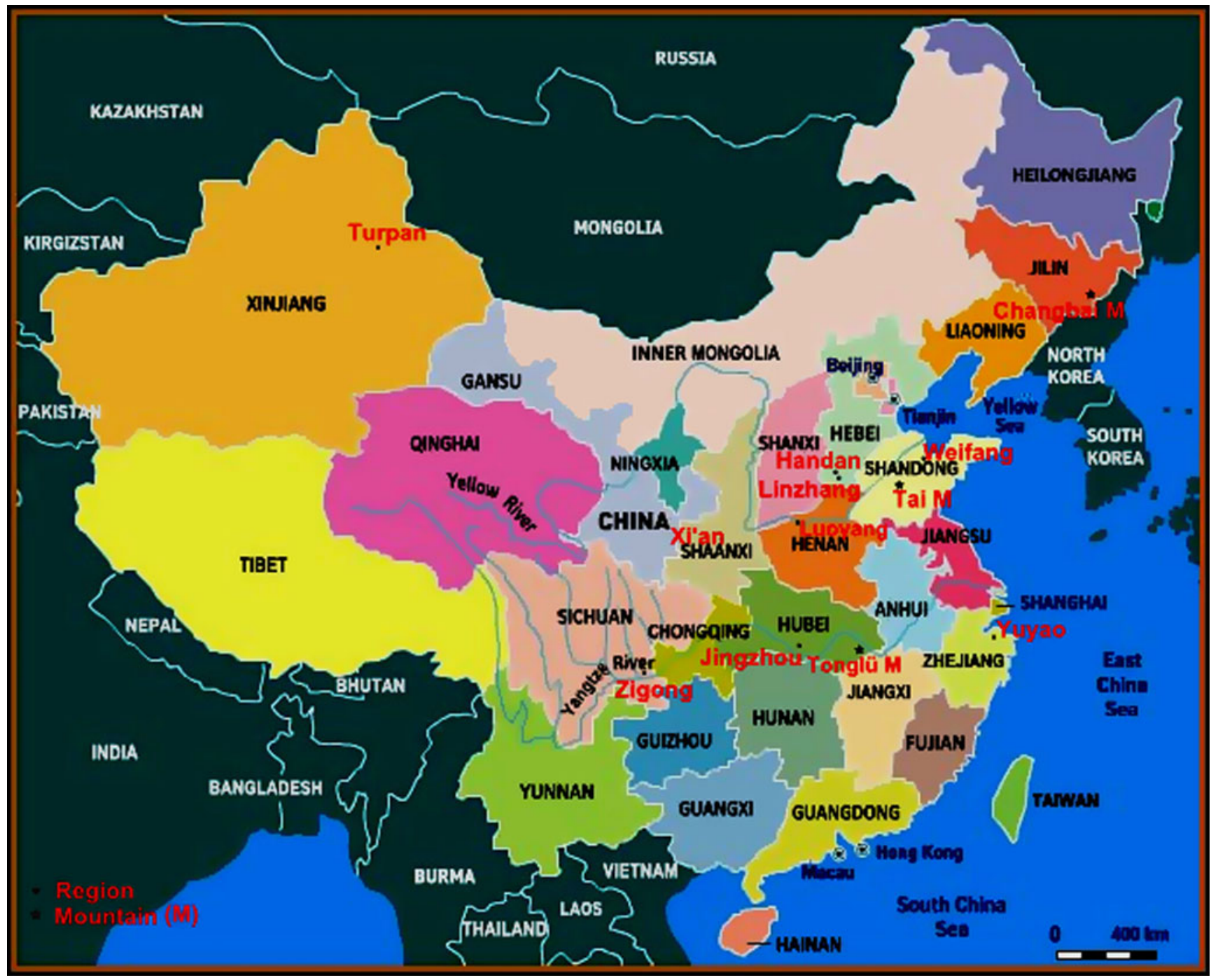

Fig. 9 Map of China with the main locations mentioned in this report, adapted from China Tells (2009)

\section{References}

Chen MJ (1956) Review of Yinxu divination. Monographs of Chinese archaeology, series A (2) (in Chinese). Science Press, Beijing

China Tells (2009) All about China. Available at: http://blog.chinatells. com/2009/08/1271/china-map. Cited 03 November 2010

Chinabaike (2007) Ancient drilling techniques in China. http:// www.chinabaike.com/article/1/78/433/2007/20070520113371. html. Cited 21 October 2010

Jiao JJ (2007) A 5,600-year-old wooden well in Zhejiang Province, China. Hydrogeol J 15:1021-1029

Liu XZ (1963) The invention of farm implements in ancient China (in Chinese). Science Press, Beijing

Liu J, Yao CY (1993) Hemudu culture of China (in Chinese with English translation). People's Publishing House of Zhejiang, Zhejiang, China

Shen SR (1979) Outlook on groundwater utilization in the prehistoric period based on archeological material (in Chinese). Gidrogeol Eng Geol 4:12

Shen SR (1981) The springs in Shi Jing (in Chinese). Gidrogeol Eng Geol 5:25

Shen SR, Wang YZ, Li ER (1985) Historical reading notes on hydrogeology (in Chinese). Geology Press, Beijing
The Museum of the Hemudu Site (2002) Gems of the Hemudu culture (in Chinese, English and Japanese). Cultural Relics Publishing House, Beijing

Vernadsky VI (1934) History of natural waters (in Russian). Nauka, Moscow

Wuhan College of Hydraulic and Electrical Engineering and Institute of Water Resources and Hydropower Research (1979) Chinese water conservancy history, vol 1 (in Chinese). Water Power Press, Beijing

Xia N (1977) C-14 dating and Chinese pre-historical archaeology (in Chinese). Archaeology (4):220-221

Xia WY (1979) Collations and explanations of the four sections in Lüshi Chunqiu-Shangnong etc. (in Chinese). Agricultural Press, Beijing

Xia N, Yin WZ (1982) Ancient copper mine of Tonglv Mountain in Hubei Province (in Chinese). Acta Archaeol Sin (1):3-10

Zhejiang Provincial Institute of Cultural Relics and Archaeology (2003) Hemudu: Neolithic site and its archaeological excavations, vol 1 (in Chinese). Culture Relics Publishing House, Beijing

Zhejiang Provincial Institute of Cultural Relics and Archaeology, Zhejiang Provincial Museum (1978) Findings on the excavation of Humudu sites (in Chinese). Acta Archaeol Sin 1:39-93

Zhou KY (2008) Water-lifting device in ancient China. http://www. chinabaike.com/article/baike/1002/2008/200805151493286. html. Cited 12 May 2010 